\title{
Job Quality and Workplace Gender Diversity in Europe*
}

\author{
Andrew E. Clark ${ }^{\dagger}$ Conchita D’Ambrosio, and Rong Zhu ${ }^{\S}$
}

\begin{abstract}
We here consider the relationship between workplace gender measures and employees' perceived job quality, where the former cover both the gender mix of workers with the same job title and the gender of the immediate boss. Data from the 2015 European Working Conditions Survey show that men's job evaluation is higher in gender-balanced job positions at the workplace, while that of women is higher in either gender-balanced or male-dominated positions. The gender of the immediate boss plays no significant role in employee job evaluation. There is some evidence that these correlations differ by job-quality domains. We introduce co-worker support and help, gender discrimination, and unwanted sexual attention as possible mediators of the gender-mix correlations: these change the estimated coefficients only little. Our estimated correlations could therefore reflect a pure preference for job-position gender composition. Last, we use a bounding approach to show that our main results are robust to the potential influence of unobservables. Overall, job-position gender diversity is associated with higher worker well-being.
\end{abstract}

Keywords: Perceived job quality; Job-position gender diversity; Gender of immediate boss.

JEL Classification Codes: J16; J28.

\footnotetext{
${ }^{*}$ We are grateful to the Editor (Russell Smyth) and three anonymous referees for very helpful comments. Thanks also go to the Eurofound and the UK Data Service for providing access to the European Working Conditions Survey data. Andrew Clark acknowledges financial support from the EUR grant ANR-17-EURE-0001.

${ }^{\dagger}$ Paris School of Economics - CNRS, France. E-mail: andrew.clark@ens.fr.

†Université du Luxembourg, Luxembourg. E-mail: conchita.dambrosio@uni.lu.

${ }^{\S}$ Flinders University, Australia. E-mail: rong.zhu@ flinders.edu.au.
} 


\section{Introduction}

Worker well-being is a major dimension of societal well-being, as work represents such a key part of many people's lives. The quality of jobs, as measured by either overall job satisfaction or the worker's evaluations of various job facets, is an important dimension of job well-being (Clark., 2015). Individual behaviour at work (e.g., quits, absenteeism and productivity) and firm outcomes (e.g., profitability and firm value) have been shown to depend on perceived job quality and job satisfaction (Clark, 2001; Harter et al., 2002; Green, 2010; Edmans, 2012; Gielen, 2013; Jones et al., 2016; Bellet et al., 2019). One strand of worker well-being research has looked at the role of the social context of the job. ${ }^{1}$ One part of latter is the gender dimension at the workplace: this is arguably of increasing practical interest given the substantial rises in women's labour-force participation across the world in recent decades (Balleer et al., 2014; Cipollone et al., 2014). At the same time, women occupy a small but rising share of managerial and supervisory positions (Kunze and Miller, 2017; Bertrand et al., 2019). ${ }^{2}$

Previous research has focussed on two aspects of gender dimensions at work: (i) the gender of the boss and (ii) the gender diversity across the whole workplace. With respect to the former, Artz and Taengnoi (2016) consider data from the US National Longitudinal Survey of Youth (NLSY79) and the 2008 National Study of the Changing Workforce, and find that women are less satisfied with their jobs when their boss is a woman, with there being no effect on men's satisfaction. Female leadership is associated with less gender discrimination for women in Lucifora and Vigani (2016) but greater discrimination for men, with the former effect being larger than the latter. Kunze and Miller (2017) show that female representation in leadership confers positive spillover benefits on women in lower ranks, and that female bosses can help narrow the gender gap in worker promotions. Moreover, in Flabbi et al. (2019), female leadership has a positive effect at the top end of the female

\footnotetext{
${ }^{1}$ One such aspect of the social context is co-worker wages. While a great deal of work has found a negative correlation between individual subjective well-being and others' wages, the situation within the firm is somewhat different, as co-workers' wages may provide information about one's own future prospects. In both Clark et al. (2009) and Javdani and Krauth (2020) individual job satisfaction is higher when colleagues in the same establishment earn more. On the contrary, Card et al. (2012) examine the effect of disclosing information on peer workers' salaries on job satisfaction. Workers whose salaries are below the median for their pay unit and occupation report lower job satisfaction when they find out about their relative standing; the job satisfaction of those above the median is not affected by this information.

${ }^{2}$ Across the OECD, 32.4\% of managers were women in 2018 (see https://stats.oecd.org/index.aspx?queryid=54752).
} 
wage distribution but a negative effect at the bottom; the impact on the male wage distribution is the opposite.

An existing literature has shown that firm-level gender diversity is linked to lower individual wages (Niebuhr and Peters, 2020) but better chances of firm survival (Backman and Kohlhase, 2020). In Garnero et al. (2014), gender diversity generates significant gains in firm-level value-added and average earnings in high-tech/knowledge-intensive sectors, while the opposite holds in more traditional industries. Hirsch et al. (2020), however, report no relation between firm-specific gender diversity and workers' job switching.

The relationships between workforce gender composition and employee job evaluations may either be instrumental (for reasons of wages or working conditions, for example) or reflect a "pure" preference for having a particular type of workplace colleague. A fairly limited literature in Economics has addressed this issue. Bender et al. (2005) use the US National Study of the Changing Workforce and find that women report higher job satisfaction in female-dominated workplaces for reasons of job flexibility. Using data from the 2004 British Workplace Employment Relations Survey, Haile (2012) shows that workplace gender diversity reduces the job-related well-being of women, but not men. Qian and Fan (2019) use data from the American Time Use Surveys to show that women report more unpleasantness and less meaningfulness when working in occupations with higher proportion of male workers, but there is no such relationship for men.

We here use data from the 2015 European Working Conditions Survey (EWCS) to contribute to this literature by relating perceived job quality to both (i) the gender composition of workers with the same title in the same organisation (we will call these co-workers below, for convenience) and (ii) the gender of the immediate supervisor. Our results show that men reported highest perceived job quality when there is an equal job-position gender mix, while women's job evaluations are lower when co-workers are mainly women (as compared to an equal split or mainly men). The gender of the immediate boss is not significantly correlated with either male or female job evaluations.

These gender-equality correlations could reflect a pure preference for diversity; on the contrary, they may also be instrumental. We look at a set of potential mediators: support and help from 
co-workers, discrimination based on gender, and unwanted sexual attention at the workplace. We find that little of gender preferences is mediated by these factors. We suggest that the remaining aversion towards to a "same-sex" majority of co-workers at the workplace may reflect greater competition for pay raises or promotion among same-sex workers, particularly when they share the same job title (Wittchen et al., 2013). In addition, men working in female-dominated occupations may suffer from negative stereotyping, and therefore report lower job evaluations (Lupton, 2000; Torre, 2018); on the contrary, women may not report lower job quality in male-dominated working environments, as these jobs may confirm their economic and social advancement (England, 2010; Moore, 2018).

We next examine potential heterogeneity in the correlations between workplace gender measures and workers' perception of job quality by the different dimensions of the job. There is considerable homogeneity. Men report (weakly) higher job evaluations when there is gender diversity for all job domains bar one: relationships with colleagues, which are reported to be better when co-workers are mostly men. Similarly, women's lower job evaluations when co-workers are mostly female are not found with respect to job security. While there was no correlation with overall job evaluation, having a female boss is weakly associated with lower pay, job prospects and motivation for men. Female leadership is also linked to a sentiment of worse pay for women. Last, using the bounding approach of Oster (2019), we show that our baseline estimates are robust to accounting for the potential confounding influence of unobserved factors.

Our work here contributes to the literature in three ways. We first present novel evidence of the relationship between employee-perceived job quality and the gender composition of the workplace at both the horizontal (among workers with the same title in the same organisation) and vertical (immediate boss) levels. ${ }^{3}$ We find that horizontal gender diversity is associated with more-positive job evaluations, which is new in the empirical literature. If we are to take these results causally, then moves to promote gender diversity and equity at the workplace (Azmat, 2019; Fine et al., 2020) will not necessarily make either men or women less positive about their work. Second, we consider a

\footnotetext{
${ }^{3}$ In contrast, previous studies generally focus on the impact of gender diversity across the whole workplace on worker well-being (Bender et al., 2005; Haile, 2012; Qian and Fan, 2019).
} 
set of potential job characteristics that may lie behind job-position gender preferences. Last, our use of the 2015 EWCS data covering 35 European countries is one of the first cross-country analyses of the empirical links between workplace gender dimensions and employee-perceived job quality. As such, they may have greater external validity than those estimated on data from only one single country.

The remainder of the paper is organised as follows. Section 2 describes the data and presents some summary statistics, and Section 3 discusses the empirical approach. Section 4 then presents the estimation results and Section 5 concludes.

\section{Data, Variables, and Descriptive Statistics}

\subsection{Data}

Our data come from the European Working Conditions Survey (EWCS), which is an authoritative source of cross-country information on working conditions across Europe. Starting in 1990, every five years the EWCS asks questions about a wide-ranging set of topics covering worker characteristics, job attributes, and working conditions. We here use the data from the sixth wave of the EWCS, the latest currently-available and the only one that includes the complete set of variables that we will use in our analysis. This wave was carried out between February and September 2015, and covered many different facets of work in 35 European countries (Eurofound, 2017). ${ }^{4}$ We restrict our empirical analysis to employees and exclude the self-employed. ${ }^{5}$ After dropping observations with missing information on the core variables that are summarised in Table 1, our final sample consists of 24,066 employees, with 11,797 men and 12,269 women.

\footnotetext{
${ }^{4}$ These 35 countries are: Albania, Austria, Belgium, Bulgaria, Croatia, Cyprus, the Czech Republic, Denmark, Estonia, Finland, France, Germany, Greece, Hungary, Ireland, Italy, Latvia, Lithuania, Luxembourg, Malta, Montenegro, Netherlands, Norway, North Macedonia, Poland, Portugal, Romania, Serbia, Slovakia, Slovenia, Spain, Sweden, Switzerland, Turkey and the United Kingdom.

${ }^{5}$ About $18 \%$ of respondents in the sixth wave of EWCS were self-employed, and $82 \%$ employees. Over half of the self-employed reported that nobody else had the same job title as them at their place of work, and under $2 \%$ reported having an immediate boss.
} 


\subsection{Key Variables}

Our main measure of perceived job quality is derived from respondents' answers to the following six statements about their job: (i) "considering all my efforts and achievements in my job, I feel I get paid appropriately"; (ii) "my job offers good prospects for career advancement"; (iii) "I receive the recognition I deserve for my work"; (iv) "I generally get on well with my work colleagues"; (v) "the organisation I work for motivates me to give my best job performance"; and (vi) "I might lose my job in the next 6 months". Respondents were asked to answer each of these on a five-point scale, where 1 refers to "Strongly Agree" and 5 to "Strongly Disagree"; the distributions of the responses to these six statements appear in Appendix Table A1. For the first five job statements we re-scale the answers (as 6-score) so that higher numbers refer to a more positive evaluation of the job for all six facets.

We then calculate an overall measure of job quality via a principal component analysis (PCA) of these six job variables. As the responses are on a five-point Likert scale, we use the polychoric PCA for ordinal scale items. ${ }^{6}$ Applying the eigenvalue-one criterion, we retain the first component that has an eigenvalue of above 1 . This principal component explains about $49 \%$ of the variation in the six job facets. We standardise this polychoric PCA index of job quality to have a mean of zero and a standard deviation of one. ${ }^{7}$

Our key explanatory variables refer to the gender composition of the workplace. EWCS respondents were first asked about the gender composition of workers at their workplace who share the same job title, with responses (i) "Mostly men", (ii) "Mostly women”, (iii) "Approximately equal numbers of men and women", and (iv) "Nobody else has the same job title". Around 17\% of employees reported that nobody else had the same title at their place of work, and our analysis sample will consist only of employees who answered (i), (ii) or (iii) to this question. This is a horizontal gender-mix question, as it refers to other workers with the same job title in the same organisation. Second, respondents were

\footnotetext{
${ }^{6}$ Appendix Tables A2 and A3 show the polychoric PCA results, with the former showing the eigenvalues of the PCA components and the latter the factor loadings on each job-evaluation item.

${ }^{7} \mathrm{We}$ also calculated an alternative measure of overall job quality as the unweighted mean of these re-scaled job-statement responses. The results, in Appendix Table A4, from this new measure are very similar to the baseline estimates in Table 3.
} 
asked about the gender of their immediate boss. Compared to other people who hold senior positions in the same organisation, the immediate boss, who is responsible for the employee's workload, pay, performance reviews and career advancement, probably matters the most for respondents' subjective evaluation of job quality. This variable, together with the employee's own gender, allows us to see whether there is a vertical gender match or mismatch between the respondent and his/her direct supervisor.

\subsection{Descriptive Statistics}

Table 1 lists respondent summary statistics, both overall and by gender. The male-female employee split in the EWCS is almost 50:50. The polychoric PCA index of perceived job quality in the first row is higher for men than for women, with the Mann-Whitney test in the last column indicating that this difference is statistically significant. ${ }^{8}$

There is an obvious match between own gender and that of co-workers, with over two-thirds of employees reporting that identically-titled workers in the organisation are mostly of the respondent's own gender. This matching is the same for men and women. Equally, a little over half of female employees have an immediate supervisor who is a woman, while this figure is only one in seven for men. The correlation coefficient between the dummies for co-workers being mostly women and having a female boss is fairly large at 0.49 . We will jointly include the horizontal and vertical gender-mix variables in our empirical analyses, to separately identify the correlations with co-workers and the supervisor.

Table 1 also shows that sample employees are on average in their early 40's, and around 40\% of women but only $30 \%$ of men have tertiary education. With respect to the family, two-thirds of respondents are married and average household size is a little under three. Both men and women

\footnotetext{
${ }^{8}$ Using overall job satisfaction as a measure of job quality, previous work has found a gender-job satisfaction paradox: women often report higher levels of job satisfaction than men (Clark, 1997; Bender et al., 2005; Perugini and Vladisavljevic, 2019). However, using data from the same EWCS survey as analysed here, Pita and Torregrosa (2020) show that the gender gap in job satisfaction has declined over time, with substantial cross-country differences, and conclude that the gender-job satisfaction paradox cannot be considered as universal. Equally, Green et al. (2018) consider more recent waves of the same BHPS data as initially analysed in Clark (1997) and conclude that the gender-job satisfaction gap in the UK eroded to zero over time.
} 





have the same number of years of tenure with the current employer. However, women work for about five fewer hours per week and are less likely to have full-time jobs. They are also less likely to be managers and more likely to work in the public sector. Last, consistent with the literature on the gender pay gap in Europe (Arulampalam et al., 2007; Redmond and McGuinness, 2019), female employees in our EWCS data earn about $22 \%$ less in terms of net monthly income than their male counterparts. Controlling for the number of hours worked, women's hourly wages are $11 \%$ lower than those of men.

\section{Empirical Strategy}

We use employee data from the 2015 EWCS to estimate the following equation:

$$
J Q_{i c s}=\text { MostlyWomen }_{c s} \beta_{1}+\text { MostlyMen }_{c s} \beta_{2}+\text { FemaleBoss }_{i c s} \gamma+X_{i c s}^{\prime} \sigma+\epsilon_{i c s}
$$

where $J Q_{i c s}$ denotes the standardised polychoric PCA measure of overall job quality of employee

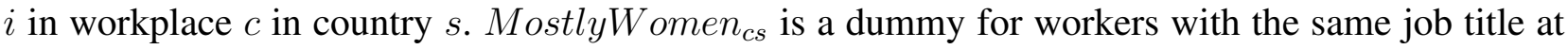
employee $i$ 's workplace being mostly women; MostlyMen ${ }_{c s}$ is defined analogously. The omitted category here is an equal workplace gender mix. FemaleBoss $s_{i c s}$ is a dummy for the employee's immediate boss being a woman. $X_{i c s}$ is a vector of control variables including age, age-squared, education dummies, a dummy for being married, household size, tenure with the current employer, a dummy for having a full-time job, a dummy for supervising people in the job, establishment-size dummies, a dummy for working in the public sector, and occupation, industry and country dummies. Last, $\epsilon_{i c s}$ is the idiosyncratic error term.

Equation (1) will be estimated via Ordinary Least Squares (OLS). The OLS estimates of $\beta_{1}$, $\beta_{2}$ and $\gamma$ measure the associations between the workplace gender measures and the job quality of EWCS employees. To look for gender differences, we will also carry out separate estimations for men and women. We cluster standard errors at the country level to account for heteroskedasticity and any arbitrary correlations across employees within the same country. 


\section{Results}

\subsection{Main results}

Table 2 presents initial OLS estimates of Equation (1), using a parsimonious model specification that includes only country dummies in $X_{i c s}$. Column (i) shows the results for the pooled sample of men and women. Compared to a job in which there is a balanced gender-mix of co-workers sharing the same job title, reported job quality is about 0.14 of a standard deviation lower if the co-workers are mostly women, and one-tenth of a standard deviation lower if they are mostly men. Job evaluation is uncorrelated with the gender of the immediate boss. Columns (ii) and (iii) of Table 2 then show the separate results for men and women. Men have a marked preference for gender balance in job positions, with perceived job quality being lower in either mostly-female or mostly-male jobs. Women report lower job evaluations in mostly-female jobs, and the same level of job quality in both gender-balanced and male-dominated jobs. With no controls other than country dummies, we thus find that job-position gender diversity is associated with workers who reported higher quality of working environment across Europe.

Table 2: Job Quality and Gender Diversity (Parsimonious Specification)

\begin{tabular}{llll}
\hline & (i) & (ii) & (iii) \\
& All & Men & Women \\
\hline Workers with the same title are mostly women & $-0.136^{* * *}$ & $-0.089^{* * *}$ & $-0.130^{* * *}$ \\
& $(0.025)$ & $(0.030)$ & $(0.026)$ \\
Workers with the same title are mostly men & $-0.103 * * *$ & $-0.132^{* * *}$ & 0.002 \\
& $(0.028)$ & $(0.032)$ & $(0.033)$ \\
Immediate boss is a woman & -0.021 & -0.031 & -0.016 \\
& $(0.015)$ & $(0.029)$ & $(0.020)$ \\
Observations & 24,066 & 11,797 & 12,269 \\
$R^{2}$ & 0.053 & 0.052 & 0.058 \\
\hline
\end{tabular}

Notes: The dependent variable is the standardised polychoric PCA index of overall job quality. Standard errors clustered at the country level appear in parentheses. All columns include country dummies. $* * *$ $p<0.01 ; * * p<0.05 ; * p<0.10$.

Table 3 shows the baseline OLS estimates of Equation (1), using the full set of control variables discussed in Section 3. The additional control variables here help address the issue of different 
Table 3: Job Quality and Gender Diversity (Baseline Estimates)

\begin{tabular}{llll}
\hline & (i) & (ii) & (iii) \\
& All & Men & Women \\
\hline Workers with the same title are mostly women & $-0.098^{* * *}$ & $-0.081^{* * *}$ & $-0.101^{* * * *}$ \\
& $(0.021)$ & $(0.029)$ & $(0.022)$ \\
Workers with the same title are mostly men & -0.036 & $-0.049 *$ & -0.016 \\
& $(0.024)$ & $(0.026)$ & $(0.034)$ \\
Immediate boss is a woman & $-0.026^{*}$ & -0.043 & -0.019 \\
& $(0.016)$ & $(0.028)$ & $(0.021)$ \\
Observations & 24,066 & 11,797 & 12,269 \\
$R^{2}$ & 0.099 & 0.106 & 0.104 \\
\hline
\end{tabular}

Notes: The dependent variable is the standardised polychoric PCA index of overall job quality. The control variables include age, age-squared, education dummies, a dummy for being married, household size, tenure with current employer, having a full-time job, a dummy for supervising people in the job, establishment-size dummies, a dummy for working in the public sector, and occupation, industry, and country dummies. The full set of estimated coefficients appear in Appendix Table A5. Standard errors clustered at the country level appear in parentheses. $* * * p<0.01 ; * * p<0.05 ; * p<0.10$.

kinds of workers selecting into jobs with different gender mixes. The results are similar in nature to those in Table 2. The resulting estimates on the workplace gender-mix variables with are slightly smaller. ${ }^{9}$ Men continue to have a significant preference for gender balance at the workplace; both mostly women and mostly men among co-workers of the same title are associated with reduced perceptions of job quality (with equally-sized estimated coefficients: $p$-value $=0.33$ ). Women report lower job quality when their co-workers are mostly women, with job quality being the same in gender-balanced and male-majority job positions. ${ }^{10}$ Job evaluation for both sexes continues to be uncorrelated with the gender of the immediate supervisor. ${ }^{11}$

\footnotetext{
${ }^{9}$ We obtain similar results when we add the log of monthly income and weekly working hours to the controls: See Appendix Table A6.

${ }^{10}$ While our primary focus here is on employees' perceived job quality, we have also looked at their satisfaction with working conditions (there is no overall job satisfaction question in the EWCS). In EWCS, workers were asked "On the whole, are you very satisfied, satisfied, not very satisfied or not at all satisfied with working conditions in your main job?". The ordered-probit estimation of the responses to this question produced results with patterns remarkably similar to those in Table 3. These results are available upon request.

${ }^{11}$ This finding partly concords with the US results in Artz and Taengnoi (2016), where men's job satisfaction was independent of supervisor gender, but that of women was lower. In a related contribution, Bednar and Gicheva (2014) find no evidence that supervisor gender predicts their female-friendliness. Bagues et al. (2017) show that women in scientific committees are not more favorable towards female candidates when evaluating applications to Associate and Full Professorships.
} 


\subsection{Other Mechanisms}

The results above show that neither demographic controls nor a set of standard job-related variables explain why workers seem to have a preference for a gender mix of co-workers. We here consider a set of variables as possible mediators of this relationship. We first look at the degree of help and support workers receive from colleagues at their workplace, answered on the scale "Always", "Most of the Time", "Sometimes", "Rarely" and "Never". We calculate a set of dummies indicating the different levels of co-worker support and help. As discussed in Niebuhr and Peters (2020), workplace diversity may lead to productivity gains because diversified workers may have complementary skills and complement each other in production processes. As such, the gender composition of co-workers may indicate the types of support and help an employee can receive in the working environment, which then subsequently affect perceived job quality.

Our next two mechanisms cover employees' experience of "discrimination on the basis of sex" and "unwanted sexual attention" during the course of their work. These two potential mediators have been found to relate to both sex composition at the workplace and job evaluations. ${ }^{12}$ For example, Stainback et al. (2011) show that the experience of gender discrimination declines for both genders when they are part of the numerical majority of their work group. Shaffer et al. (2000) find that gender discrimination is associated with reduced job satisfaction and increased turnover intentions and life stress. Unwanted sexual attention is also negatively related to job evaluations (Clarke et al., 2016).

The summary statistics for all of these possible mediators appear in Appendix Table A7: these show that more women than men (3\% compared to 1\%) report discrimination or unwanted sexual attention. We can also calculate the incidence of these variables according to the gender mix of the workplace. Both men and women report more unwanted sexual attention in opposite-sex dominated workplaces, although the differences (at one percentage point) are small. There are larger gaps with respect to discrimination. Only one percent of men report discrimination in male-dominated workplaces, rising to four percent in female-dominated workplaces; the respective figures for women

\footnotetext{
${ }^{12}$ In the EWCS data, we are unable to rule out the possibility that these three potential mediators may have affected the gender composition among co-workers.
} 
are nine and two percent.

Column (i) of Table 4 reproduces the estimates from the baseline specification in Table 3 , for comparison purposes; Columns (ii)-(iv) then separately add the three sets of mediating variables to the baseline specification, and Column (v) includes all three at the same time. In Panel A, for men, the negative coefficient on female co-workers appears to be slightly smaller when we control for all three mediators (although we cannot reject the hypothesis that this estimated coefficient is the same as that in Column (i)). The inspection of the estimated coefficients in Columns (ii)-(v) of Panels A and B suggests that for both men and women the inclusion of mediators has very little effect on the relationship between perceived job quality and co-worker gender diversity.

In Table 3 neither men's nor women's job quality was correlated with the gender of the immediate boss. The addition of the mediators changes this story somewhat: in Column (v) of Table 4, with all three mediators, having a female boss is associated with lower job evaluations for both sexes. The comparison of the estimated coefficients in Columns (ii)-(v) to the baseline estimates in Table 3 reveals that this change is due to support from colleagues for both sexes, so that positions with a female boss provide somewhat more support. Conditional on the mediators included, perceived job quality is lower for those having a female supervisor.

These mediators therefore play little or no role for co-worker gender diversity for both men and women. A natural question is then what lies behind the reference for gender equality among co-workers, where neither men nor women prefer having a majority of same-sex co-workers. One possibility is that the competition for pay rises or promotion may be more intense among same-sex co-workers, particularly when they share the same job title (Wittchen et al., 2013). Men's lower perceived job quality in female-dominated workplaces may, in addition to the mediators considered in Table 4, reflect the negative stereotyping discussed in Lupton (2000) and Torre (2018). However, women in male-dominated fields may not suffer from negative stereotyping and even consider their job as an important signal of economic and social advancement (England, 2010; Moore, 2018). ${ }^{13}$

\footnotetext{
${ }^{13}$ There has been increasing female participation in male-dominated occupations, while men are reluctant to work in female-dominated fields (England, 2010; Torre, 2018).
} 


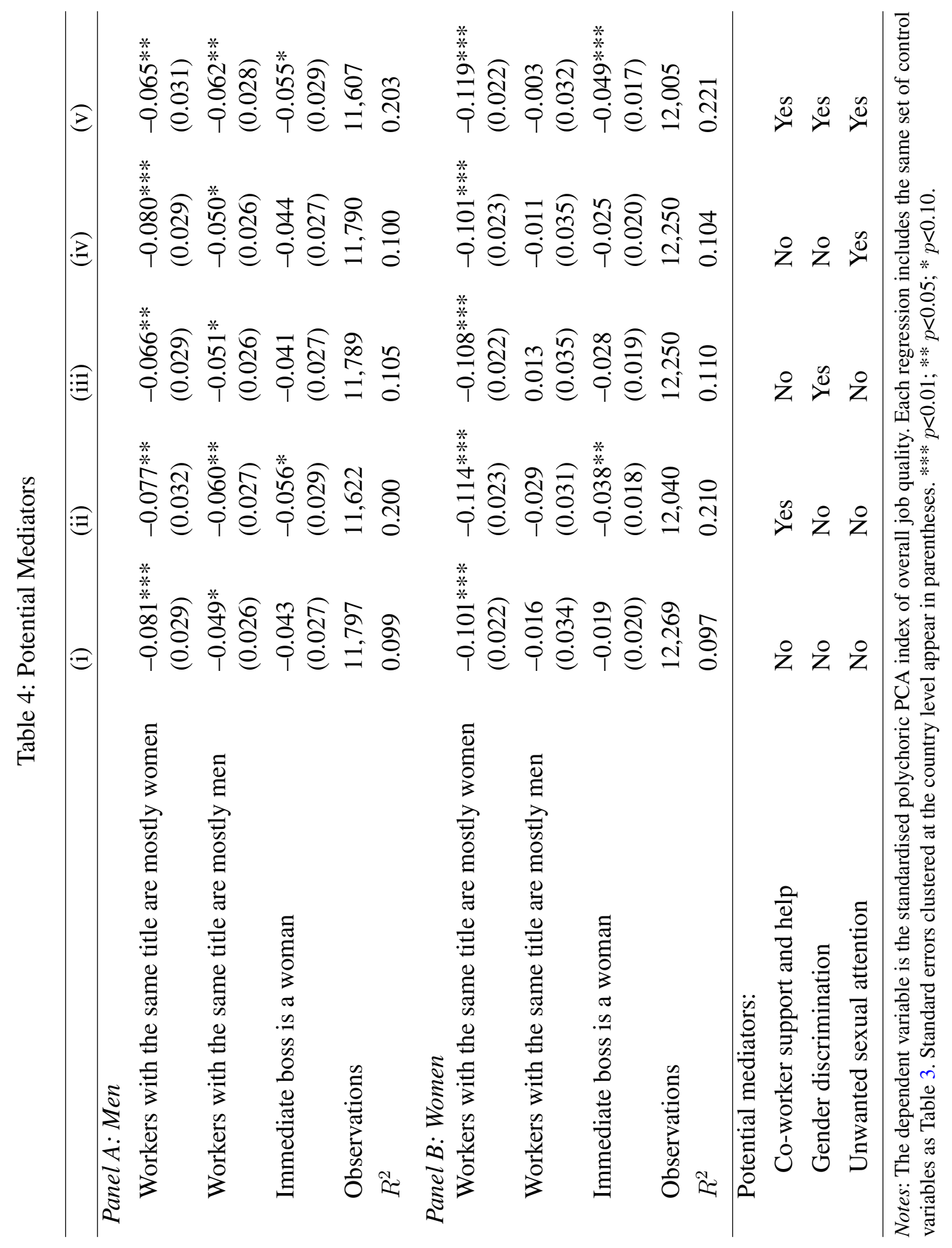




\subsection{Different Domains of the Job}

While we have found that the gender mix of co-workers is an important correlate of employees' overall evaluation of their job, it is of interest to see whether the correlations are the same for all of the six job domains used in the polychoric principal components analysis. As described in Section 2.2, these refer to "Appropriate Pay", "Promotion", "Recognition", "Relations with work colleagues", "Motivation", and "Job security". ${ }^{14}$ All six indicators are measured on a one to five scale, where higher numbers refer to better outcomes; we standardise each measure to have zero mean and unit variance. Table 5 shows the results from the OLS estimation of each job domain, using the same specification as in Table 3.

The results in Table 5 actually reveal considerable homogeneity by both job domain and employee gender. Most of the estimated workplace-gender variables have (statistically) the same estimated coefficient in each job domain. Men report (weakly) better outcomes when there is gender diversity for all job domains bar one: the exception is relationships, which are reported to be better when co-workers are majority male. Similarly, women's lower job evaluations when co-workers are mostly female are not found for relationships and job security. Gender at the workplace has no correlation with relationship quality for women. Female workers have higher sense of job security when their co-workers are mostly women, and male majority co-workers are associated with lower motivation. Last, while there was no relationship with overall job evaluation in Table 3, the last row of each panel in Table 5 indicates that having a female boss is weakly associated with lower pay, job prospects and motivation for men, and a sentiment of being less-well paid for women. Previous work has underlined that women are less likely to embrace competitive activities such as negotiation and bargaining than men (Niederle and Vesterlund, 2007; Artz and Taengnoi, 2016; Save-Soderbergh, 2019). If this is true for female supervisors, their employees may believe that their female supervisor has not bargained sufficiently for subordinates' salaries. Another possible explanation is that female bosses are paid less than male bosses (Munoz-Bullon, 2010; Geiler and Renneboog, 2015), and their

\footnotetext{
${ }^{14} \mathrm{We}$ also explored potential heterogeneity in the relationship between perceived job quality and job-position gender mix by employee characteristics, including (i) age (45 or below vs. over 45), (ii) education (tertiary education or not), (iii) managerial status, and (iv) sector (public or private). We found little evidence of heterogeneity in these four dimensions.
} 


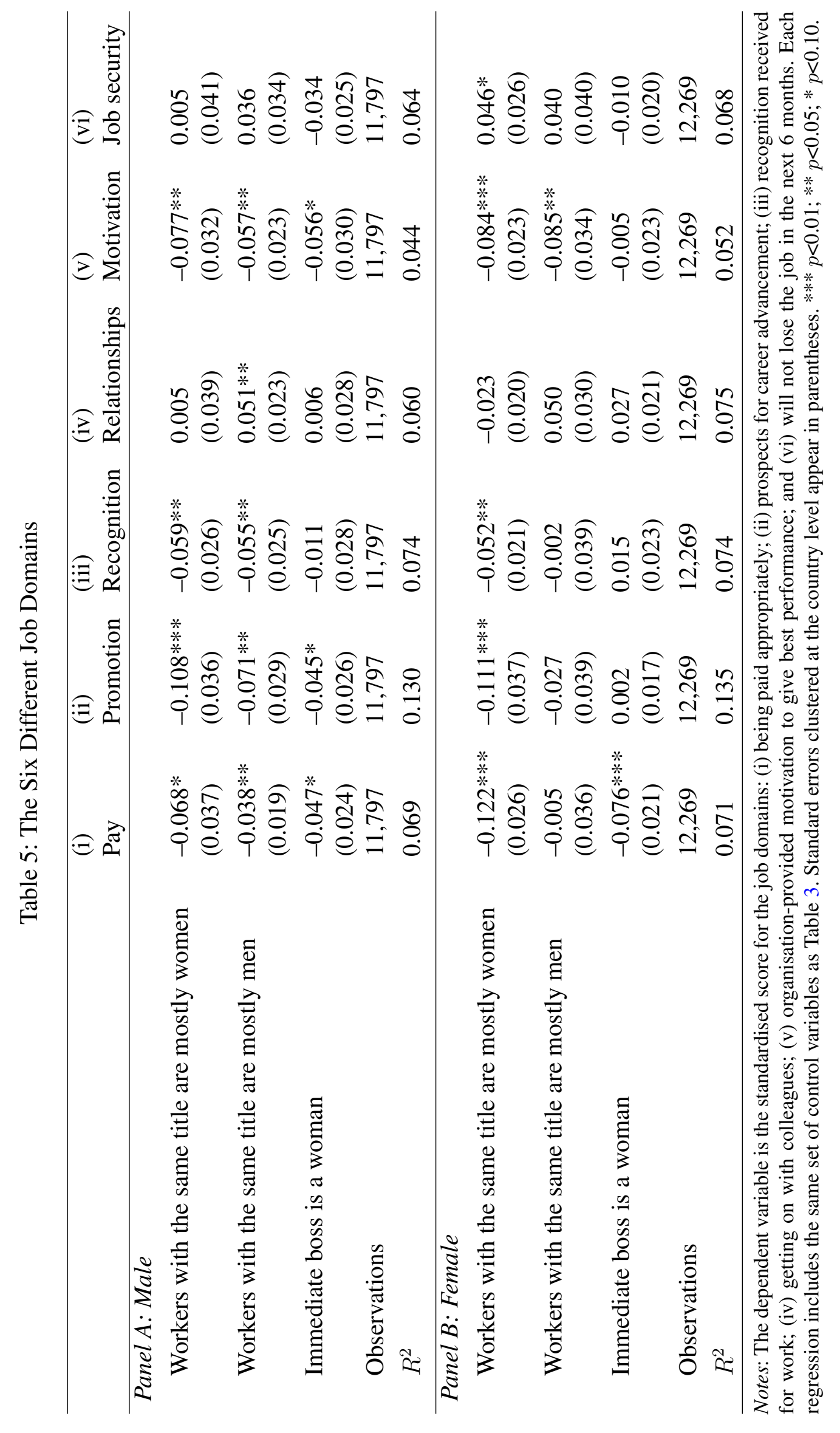


subordinate workers may vicariously take this into account in their evaluation of their own pay.

\subsection{Bounding the Estimates}

It is natural to ask whether our baseline estimates in Table 3 are causal. Unobserved selection into workplaces and heterogeneity may produce correlations with gender diversity and employee job evaluations. Jobs in titles where workers are predominantly women may have unobservable worse working conditions, for example, producing the negative correlation for both sexes in the first line of Table 3. With there being no suitable instruments for the gender of co-workers or the immediate boss in the EWCS data, we turn to a bound analysis. Bounding allows partial identification of the impact under investigation by constructing consistent bounds on the true value that would have been obtained with full information on the observed and unobserved variables. The bounds evaluate the extent of selection on unobservables.

The potential bias from omitted variables is evaluated by exploring the sensitivity of estimated coefficients to the inclusion of observed covariates. Coefficients that remain stable after the inclusion of observed control variables can be interpreted as revealing limited omitted-variable bias (Altonji et al., 2005). However, Oster (2019) argues that the value of $R^{2}$ should also be taken into account, as coefficient estimates may remain stable due to the inclusion of uninformative controls. Oster proposes a method of deriving bound estimates, incorporating the $R^{2}$ value into the method in Altonji et al. (2005).

We here use the approach of Oster (2019), which requires two pieces of information to establish the bound estimates. The first is the value of $\delta$, which measures the relative degree of selection on observed and unobserved variables. Oster (2019) suggests using $\delta=1$ : the selection on observables is the same as that on unobservables. The second is the $R^{2}$ from a hypothetical regression of the dependent variable on the treatment variable and both the observed and unobserved controls (denoted by $R_{\text {Max }}^{2}$ ). Oster (2019) suggests that $R_{\text {Max }}^{2}$ be set equal to $\operatorname{Min}\left\{1,1.3 \widehat{R}^{2}\right\}$, where $\widehat{R}^{2}$ is obtained from the baseline regression with controls included in Equation (1). ${ }^{15}$ The identified set

\footnotetext{
${ }^{15}$ In empirical settings, an outcome variable is not likely to be fully explained even with a full set of controls, for reasons such as measurement error. As such, $R_{\text {Max }}^{2}$ is not necessarily equal to one. The value of $1.3 \widehat{R}^{2}$ suggested is
} 


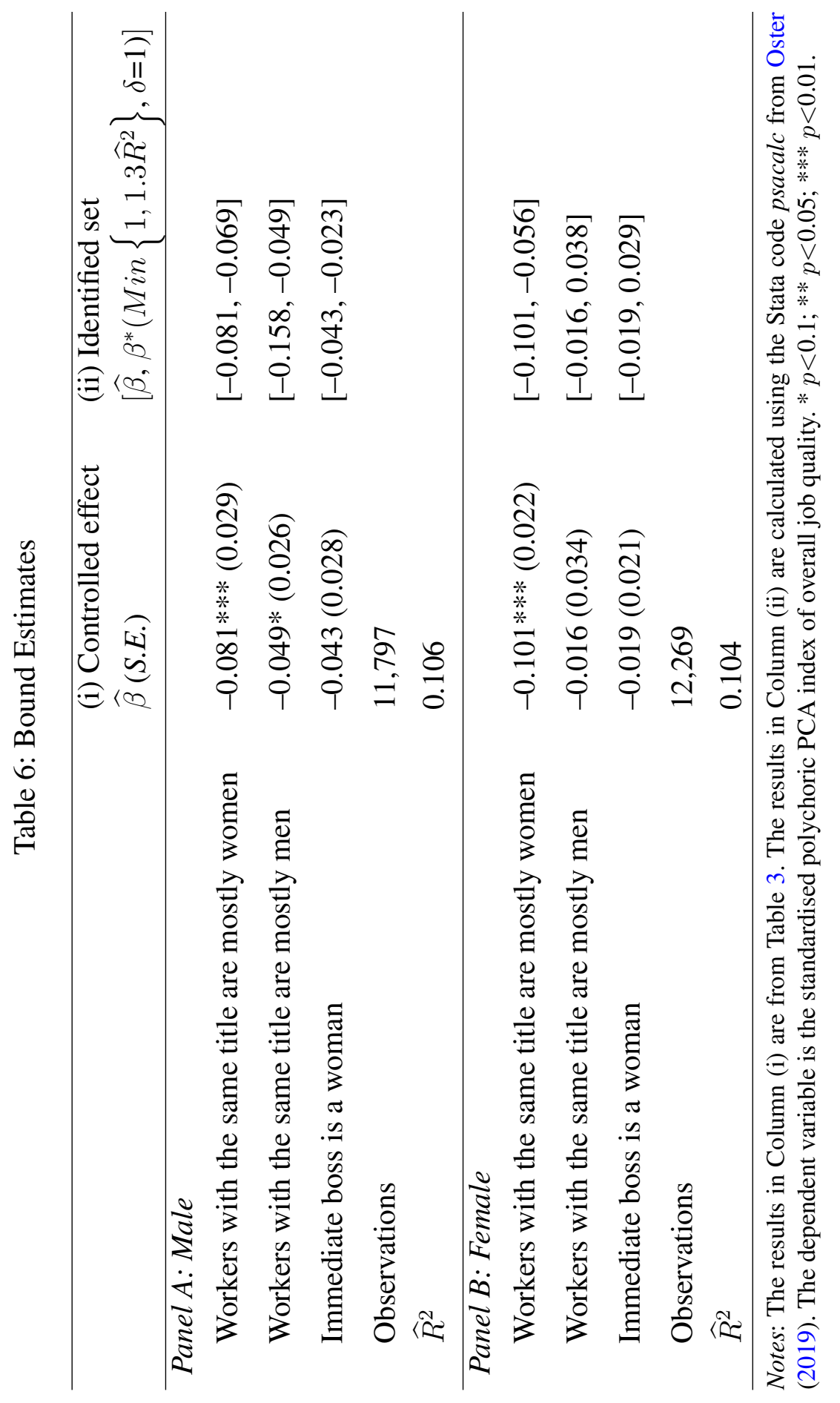


(or bounds) $\left[\widehat{\beta}, \beta^{*}\left(R_{M a x}^{2}, \delta=1\right)\right]$ is given by $\left[\widehat{\beta}, \beta^{*}\left(\operatorname{Min}\left\{1,1.3 \widehat{R}^{2}\right\}, \delta=1\right)\right]$, which includes the true estimate. ${ }^{16}$ Here $\beta^{*}$ is estimated as $\widehat{\beta}-(\stackrel{\circ}{\beta}-\widehat{\beta}) \frac{R_{M a x}^{2}-\widehat{R}^{2}}{\widehat{R}^{2}-\AA^{2}}$, where $\stackrel{\circ}{\beta}$ and $\stackrel{\circ}{R}^{2}$ are obtained from the OLS regression of the dependent variable on the treatment variable using no controls, and $\widehat{\beta}$ and $\widehat{R}^{2}$ are from the baseline regression with observed controls (as in Equation (1)). The results from the bound analyses are easy to interpret: if the bounded set excludes zero, then the true effect of each treatment on the outcome variable is not zero (Oster, 2019). In this case, the identified set indicates that the baseline estimates are robust.

As we have found gender differences in the relationships between employee job evaluations and workplace gender composition, we carry out the bound analysis separately for men and women. The results appear in Table 6. Column (i) presents the controlled-effect estimates (denoted by $\widehat{\beta}$ ), which are reproduced from Columns (ii) and (iii) of Table 3. The identified sets (bound estimates) are then shown in Column (ii) of Table 6. For each of the statistically-significant estimates in Column (i), the corresponding identified bounds do not include zero. Therefore, our baseline estimates seem to be robust to the potential confounding influence of unobservables. Apart from the interest in seeing whether the bounds exclude zero, we can also consider the width of the bound estimates. For same-titled workers at the workplace being mostly women, the estimated 0.081 standard-deviation reduction in men's job evaluations is robust but the bound is slightly smaller at -0.069 . The bounding analysis thus suggests a causal pathway between mostly-female co-workers and men's perceived job quality, but of a slightly smaller size than that in Table 3 after accounting for the potential influence of unobservables. We reach a similar conclusion for women's job evaluations and mostly-female co-workers. On the contrary, the results in the second row of Table 6 suggest that the causal effect of mostly-male co-workers on men's self-reported job quality is comparatively larger (i.e. more negative) than the OLS estimate.

identified by Oster (2019) from the analysis of randomised-trial results published in top Economics journals.

${ }^{16}$ The identified set can also be $\left[\beta^{*}\left(\operatorname{Min}\left\{1,1.3 \widehat{R}^{2}\right\}, \delta=1\right), \widehat{\beta}\right]$, depending on the relative size of $\widehat{\beta}$ and $\beta^{*}$. 


\section{Conclusion}

We have here used data from the 2015 European Working Conditions Survey to consider the relationship between workplace gender composition and employee job evaluations. The former is given by both the gender mix of workers with the same title at the place of work and the gender of the immediate boss. Male employees prefer workplace gender diversity, as their job evaluations are highest when there is an equal gender split amongst co-workers. Women's perceived job quality is lower in female-dominated jobs, but not in male-dominated ones. As such, the segregation of women (men) into female- (male-) dominated workplaces does not seem to reflect average worker preferences. There is no evidence across Europe that job quality perceived by male or female employees is related to the gender of the immediate supervisor.

We find that the relationships between workplace gender variables and employee-perceived job quality are stronger for some job domains than for others. Using the bounding approach, we show that our main results are robust to accounting for the potential confounding influence of unobserved variables. The correlations between the gender mix of co-workers and job evaluations are only little explained by the possible mediators of co-worker support and help, gender discrimination, and unwanted sexual attention at the workplace. Our estimated correlations could therefore reflect a pure preference for job-position gender composition at the workplace. There are, however, a number of instrumental explanations that we cannot test directly. The aversion to "same-sex" workplaces may reflect greater competition for pay rises or promotion prospects among same-sex workers who also share the same job title. In addition, men working in female-dominated occupations may suffer negative stereotyping and therefore report low quality when evaluating their job; women's perceived job quality in working environments dominated by men may not be lower, as entering male-dominated fields may confirm their economic and social advancement.

Our results here are new relative to the existing literature. Job-position gender diversity at the workplace is overall associated with more positive job evaluations, for both men and women, and neither sex benefits or loses from having a female boss. This is unlikely to be the end of the story, however. While our bound analysis suggests that our main findings are robust, we would 
also like to establish the causal estimates of workplace gender measures on employees' perceived job quality. We can probably rule out reverse causality here though, as "bad" jobs are likely to be unappealing to workers of both sexes, rather than one sex only. We cannot address potential endogeneity from omitted-variable bias via instrumental variables, as we would need multiple valid instruments (and instrumental-variable estimation with multiple endogenous regressors may well run into weak-instrument problems). Furthermore, it is not easy to think of credible quasi-experimental variations in survey data that could be used for causal identification (although it might be argued that the gender of the immediate boss is somewhat more exogenous than that of co-workers). ${ }^{17} \mathrm{~A}$ better solution to endogeneity problems than the bounding approach does not yet appear to be available in the context of our work here. Last, our job-position gender diversity measure is self-reported. Ideally, we would like to use a more objective and exogenous measure of the sex (and job titles) of others in the workplace, which is currently unavailable in the EWCS data. We leave these questions for future research.

\section{Conflict of Interest}

The authors declare no conflict of interest.

\section{References}

Altonji, J. G., T. E. Elder, and C. R. Taber (2005). Selection on observed and unobserved variables: assessing the effectiveness of Catholic schools. Journal of Political Economy 113, 151-184.

Artz, B. and S. Taengnoi (2016). Do women prefer female bosses? Labour Economics 42, 194-202.

Arulampalam, W., A. L. Booth, and M. L. Bryan (2007). Is there a glass ceiling over Europe? Exploring the gender pay gap across the wage distribution. Industrial \& Labor Relations Review 60, 163-186.

\footnotetext{
${ }^{17}$ Bertrand et al. (2019) exploit the mandated $40 \%$ representation of each gender on corporate boards in Norway, finding that the female board members appointed post-reform were more qualified than their female predecessors. They do not find any positive spillovers from greater female corporate-board representation on the outcomes of women in the organization.
} 
Azmat, G. (2019). Gender diversity in teams. IZA World of Labor, Article 29.

Backman, M. and J. E. Kohlhase (2020). Labor force diversity and firm survival. Journal of Regional Science 60, 903-928.

Bagues, M., M. Sylos-Labini, and N. Zinovyeva (2017). Does the gender composition of scientific committees matter? American Economic Review 107, 1207-1238.

Balleer, A., R. Gomez-Salvador, and J. Turunen (2014). Labour force participation across Europe: a cohort-based analysis. Empirical Economics 46, 1385-1415.

Bednar, S. and D. Gicheva (2014). Are female supervisors more female-friendly? American Economic Review 104, 370-375.

Bellet, C., J.-E. De Neve, and G. Ward (2019). Does employee happiness have an impact on productivity? Said Business School Working Paper No. 2019-13.

Bender, K. A., S. M. Donohue, and J. S. Heywood (2005). Job satisfaction and gender segregation. Oxford Economic Papers 57, 479-496.

Bertrand, M., S. E. Black, S. Jensen, and A. Lleras-Muney (2019). Breaking the glass ceiling? The effect of board quotas on female labour market outcomes in Norway. Review of Economic Studies 86, 191-239.

Card, D., A. Mas, E. Moretti, and E. Saez (2012). Inequality at work: the effect of peer salaries on job satisfaction. American Economic Review 102, 2981-3003.

Cipollone, A., E. Patacchini, and G. Vallanti (2014). Female labour market participation in Europe: novel evidence on trends and shaping factors. IZA Journal of European Labor Studies 3, Article 18.

Clark, A. E. (1997). Job satisfaction and gender: why are women so happy at work? Labour Economics 4, 341-372. 
Clark, A. E. (2001). What really matters in a job? Hedonic measurement using quit data. Labour Economics 8, 223-242.

Clark., A. E. (2015). What makes a good job? Job quality and job satisfaction. IZA World of Labor, Article 215.

Clark, A. E., N. Kristensen, and N. Westergard-Nielsen (2009). Job satisfaction and co-worker wages: status or signal? Economic Journal 119, 430-447.

Clarke, H. M., D. P. Ford, and L. M. Sulsky (2016). Moderating effects of harasser status and target gender on the relationship between unwanted sexual attention and overall job satisfaction. Journal of Applied Social Psychology 46, 701-717.

Edmans, A. (2012). The link between job satisfaction and firm value, with implications for corporate social responsibility. Academy of Management Perspectives 26, 1-19.

England, P. (2010). The gender revolution: uneven and stalled. Gender and Society 24, 149-166.

Eurofound (2017). Sixth European Working Conditions Survey: Overview Report (2017 Update). Publications Office of the European Union, Luxembourg.

Fine, C., V. Sojo, and H. Lawford-Smith (2020). Why does workplace gender diversity matter? Justice, organizational benefits, and policy. Social Issues and Policy Review 14, 36-72.

Flabbi, L., M. Macis, A. Moro, and F. Schivardi (2019). Do female executives make a difference? The impact of female leadership on gender gaps and firm performance. Economic Journal 129, $2390-2423$.

Garnero, A., S. Kampelmann, and F. Rycx (2014). The heterogeneous effects of workforce diversity on productivity, wages, and profits. Industrial Relations 53, 430-477.

Geiler, P. and L. Renneboog (2015). Are female top managers really paid less? Journal of Corporate Finance 35, 345-369. 
Gielen, A. (2013). Repeated job quits: stepping stones or learning about quality? IZA Journal of European Labor Studies 2, Article 7.

Green, C. P., J. S. Heywood, P. Kler, and G. Leeves (2018). Paradox lost: the disappearing female job satisfaction premium. British Journal of Industrial Relations 56, 484-502.

Green, F. (2010). Well-being, job satisfaction and labour mobility. Labour Economics 17, 897-903.

Haile, G. A. (2012). Unhappy working with men? Workplace gender diversity and job-related well-being in Britain. Labour Economics 19, 329-350.

Harter, J. K., F. L. Schmidt, and T. L. Hayes (2002). Business-unit-level relationship between employee satisfaction, employee engagement, and business outcomes: a meta-analysis. Journal of Applied Psychology 87, 268-279.

Hirsch, B., E. J. Jahn, and T. Zwick (2020). Birds, birds, birds: co-worker similarity, workplace diversity and job switches. British Journal of Industrial Relations 58, 690-718.

Javdani, M. and B. Krauth (2020). Job satisfaction and co-worker pay in Canadian firms. Canadian Journal of Economics 53, 212-248.

Jones, M. K., P. L. Latreille, and P. J. Sloane (2016). Job anxiety, work-related psychological illness and workplace performance. British Journal of Industrial Relations 54, 742-767.

Kunze, A. and A. R. Miller (2017). Women helping women? Evidence from private sector data on workplace hierarchies. Review of Economics and Statistics 99, 769-775.

Lucifora, C. and D. Vigani (2016). What if your boss is a woman? Work organization, work-life balance and gender discrimination at the workplace. IZA Discussion Paper No. 9737.

Lupton, B. (2000). Maintaining masculinity: men who do “women's work". British Journal of Management 11, 33-48.

Moore, T. S. (2018). Occupational career change and gender wage inequality. Work and Occupations 45, 82-121. 
Munoz-Bullon, F. (2010). Gender-compensation differences among high-level executives in the United States. Industrial Relations 49, 346-370.

Niebuhr, A. and J. C. Peters (2020). Workforce composition and individual wages - an employer-employee data analysis. British Journal of Industrial Relations 58, 719-742.

Niederle, M. and L. Vesterlund (2007). Do women shy away from competition? Do men compete too much? Quarterly Journal of Economics 122, 1061-1101.

Oster, E. (2019). Unobservable selection and coefficient stability: theory and evidence. Journal of Business \& Economic Statistics 37, 187-204.

Perugini, C. and M. Vladisavljevic (2019). Gender inequality and the gender-job satisfaction paradox in Europe. Labour Economics 60, 129-147.

Pita, C. and R. J. Torregrosa (2020). The gender-job satisfaction paradox through time and countries. Applied Economics Letters, forthcoming.

Qian, Y. and W. Fan (2019). Men and women at work: occupational gender composition and affective well-being in the United States. Journal of Happiness Studies 20, 2077-2019.

Redmond, P. and S. McGuinness (2019). The gender wage gap in Europe: job preferences, gender convergence and distributional effects. Oxford Bulletin of Economics and Statistics 81, 564-587.

Save-Soderbergh, J. (2019). Gender gaps in salary negotiations: salary requests and starting salaries in the field. Journal of Economic Behavior \& Organization 161, 35-51.

Shaffer, M. A., J. R. Joplin, M. P. Bell, T. Lau, and C. Oguz (2000). Gender discrimination and job-related outcomes: a cross-cultural comparison of working women in the United States and China. Journal of Vocational Behavior 57, 395-427.

Stainback, K., T. N. Ratliff, and V. J. Roscigno (2011). The context of workplace sex discrimination: sex composition, workplace culture and relative power. Social Forces 89, 1165-1188. 
Torre, M. (2018). Stopgappers? The occupational trajectories of men in female-dominated occupations. Work and Occupations 45, 283-312.

Wittchen, M., A. Krimmel, M. Kohler, and G. Hertel (2013). The two sides of competition: competition-induced effort and affect during intergroup versus interindividual competition. British Journal of Psychology 104, 320-338.

\section{Appendix}

Table A1: Distributions of Responses of the Different Aspects of Job Quality

\begin{tabular}{lllllll}
\hline & (i) & (ii) & (iii) & (iv) & (v) & (vi) \\
\hline Strongly agree (\%) & 16.2 & 13.9 & 22.4 & 56.6 & 22.9 & 6.9 \\
Tend to agree (\%) & 33.3 & 24.6 & 39.3 & 36.1 & 38.1 & 10.3 \\
Neither agree nor disagree (\%) & 17.6 & 22.4 & 19.8 & 5.2 & 21.7 & 15.1 \\
Tend to disagree (\%) & 18.3 & 17.8 & 10.8 & 1.4 & 10.4 & 19.9 \\
Strongly disagree (\%) & 14.6 & 21.2 & 7.7 & 0.7 & 7.0 & 47.8 \\
\hline Total (\%) & 100.0 & 100.0 & 100.0 & 100.0 & 100.0 & 100.0 \\
Observations & 24,066 & 24,066 & 24,066 & 24,066 & 24,066 & 24,066 \\
\hline
\end{tabular}

Notes: (i) "considering all my efforts and achievements in my job, I feel I get paid appropriately"; (ii) "my job offers good prospects for career advancement"; (iii) "I receive the recognition I deserve for my work"; (iv) "I generally get on well with my work colleagues"; (v) "the organisation I work for motivates me to give my best job performance"; and (vi) "I might lose my job in the next 6 months".

Table A2: Polychoric Principal Component Analysis

\begin{tabular}{llll}
\hline Component & Eigenvalue & Proportion & Cumulative \\
\hline Component 1 & 2.93 & 0.49 & 0.49 \\
Component 2 & 0.96 & 0.16 & 0.65 \\
Component 3 & 0.82 & 0.14 & 0.79 \\
Component 4 & 0.55 & 0.09 & 0.88 \\
Component 5 & 0.43 & 0.07 & 0.95 \\
Component 6 & 0.31 & 0.05 & 1.00 \\
\hline
\end{tabular}


Table A3: Contribution of the Variables to the Polychoric PCA Components

\begin{tabular}{llll}
\hline Variable & Component 1 & Component 2 & Component 3 \\
\hline (i) Pay & 0.72 & -0.19 & 0.27 \\
(ii) Promotion & 0.68 & -0.26 & 0.40 \\
(iii) Recognition & 0.82 & -0.09 & 0.05 \\
(iv) Relationships & 0.49 & 0.23 & -0.69 \\
(v) Motivation & 0.81 & -0.09 & 0.04 \\
(vi) Job security & 0.27 & 0.89 & 0.39 \\
\hline
\end{tabular}

Notes: (i) being paid appropriately; (ii) prospects for career advancement; (iii) recognition received for work; (iv) getting on with colleagues; (v) organisation-provided motivation to give best performance; and (vi) will not lose job in the next 6 months. Here we report factor loadings on each item of job statements for the first three components that jointly explain $79 \%$ of the variation in the six job facets.

Table A4: Using an Alternative Index of Job Quality

\begin{tabular}{llll}
\hline & (i) & (ii) & (iii) \\
& All & Men & Women \\
\hline Workers with the same title are mostly women & $-0.112^{* * *}$ & $-0.094^{* * *}$ & $-0.116^{* * *}$ \\
& $(0.022)$ & $(0.032)$ & $(0.023)$ \\
Workers with the same title are mostly men & $-0.044^{*}$ & $-0.057 * *$ & -0.026 \\
& $(0.025)$ & $(0.026)$ & $(0.035)$ \\
Immediate boss is a woman & -0.024 & -0.041 & -0.016 \\
& $(0.015)$ & $(0.027)$ & $(0.020)$ \\
Observations & 24,066 & 11,797 & 12,269 \\
$R^{2}$ & 0.095 & 0.098 & 0.096 \\
\hline
\end{tabular}

Notes: The dependent variable is the standardised unweighted mean of job-statement responses. Each regression includes the same set of control variables as Table 3. Standard errors clustered at the country level appear in parentheses. $* * * p<0.01 ; * * p<0.05 ; * p<0.10$. 
Table A5: Job Quality and Job-Position Gender Diversity (Full Results from Table 3)

\begin{tabular}{|c|c|c|c|}
\hline & $\begin{array}{l}\text { (i) } \\
\text { All }\end{array}$ & $\begin{array}{l}\text { (ii) } \\
\text { Male }\end{array}$ & $\begin{array}{l}\text { (iii) } \\
\text { Female }\end{array}$ \\
\hline Workers with the same title are mostly women & $\begin{array}{l}-0.098 * * * \\
(0.021)\end{array}$ & $\begin{array}{l}-0.081 \text { *** } \\
(0.029)\end{array}$ & $\begin{array}{l}-0.101 * * * \\
(0.022)\end{array}$ \\
\hline Workers with the same title are mostly men & $\begin{array}{l}-0.036 \\
(0.024)\end{array}$ & $\begin{array}{l}-0.049 * \\
(0.026)\end{array}$ & $\begin{array}{l}-0.016 \\
(0.034)\end{array}$ \\
\hline Immediate boss is a woman & $\begin{array}{l}-0.026^{*} \\
(0.015)\end{array}$ & $\begin{array}{l}-0.043 \\
(0.027)\end{array}$ & $\begin{array}{l}-0.019 \\
(0.020)\end{array}$ \\
\hline Age & $\begin{array}{l}-0.043 * * * \\
(0.006)\end{array}$ & $\begin{array}{l}-0.043 * * * \\
(0.009)\end{array}$ & $\begin{array}{l}-0.044 * * * \\
(0.006)\end{array}$ \\
\hline Age-squared/100 & $\begin{array}{l}0.044 * * * \\
(0.007)\end{array}$ & $\begin{array}{l}0.043 * * * \\
(0.010)\end{array}$ & $\begin{array}{l}0.047 * * * \\
(0.007)\end{array}$ \\
\hline Female & $\begin{array}{l}-0.002 \\
(0.023)\end{array}$ & & \\
\hline Secondary & $\begin{array}{l}0.061 \\
(0.043)\end{array}$ & $\begin{array}{l}0.058 \\
(0.063)\end{array}$ & $\begin{array}{l}0.050 \\
(0.062)\end{array}$ \\
\hline Post-secondary non-tertiary & $\begin{array}{l}0.117 * * \\
(0.055)\end{array}$ & $\begin{array}{l}0.111 \\
(0.077)\end{array}$ & $\begin{array}{l}0.103 \\
(0.074)\end{array}$ \\
\hline Tertiary education & $\begin{array}{l}0.134 * * * \\
(0.048)\end{array}$ & $\begin{array}{l}0.185 * * * \\
(0.068)\end{array}$ & $\begin{array}{l}0.075 \\
(0.073)\end{array}$ \\
\hline Married & $\begin{array}{c}-0.003 \\
(0.016)\end{array}$ & $\begin{array}{l}-0.019 \\
(0.020)\end{array}$ & $\begin{array}{l}0.010 \\
(0.025)\end{array}$ \\
\hline Household size & $\begin{array}{l}0.030 * * * \\
(0.007)\end{array}$ & $\begin{array}{l}0.030 * * * \\
(0.008)\end{array}$ & $\begin{array}{l}0.032 * * * \\
(0.009)\end{array}$ \\
\hline Tenure with current employer & $\begin{array}{l}0.002 * \\
(0.001)\end{array}$ & $\begin{array}{l}0.004 * * \\
(0.002)\end{array}$ & $\begin{array}{l}0.001 \\
(0.002)\end{array}$ \\
\hline Full-time job & $\begin{array}{l}0.197 * * * \\
(0.026)\end{array}$ & $\begin{array}{l}0.201 * * * \\
(0.033)\end{array}$ & $\begin{array}{l}0.177 * * * \\
(0.034)\end{array}$ \\
\hline Supervisory job & $\begin{array}{l}0.197 * * * \\
(0.026)\end{array}$ & $\begin{array}{l}0.201 * * * \\
(0.033)\end{array}$ & $\begin{array}{l}0.177 * * * \\
(0.034)\end{array}$ \\
\hline Establishment size $10-49$ & $\begin{array}{l}-0.007 \\
(0.035)\end{array}$ & $\begin{array}{l}-0.007 \\
(0.048)\end{array}$ & $\begin{array}{l}-0.012 \\
(0.054)\end{array}$ \\
\hline Establishment size 50-249 & $\begin{array}{l}-0.059 * * \\
(0.027)\end{array}$ & $\begin{array}{l}-0.090 * \\
(0.048)\end{array}$ & $\begin{array}{l}-0.037 \\
(0.036)\end{array}$ \\
\hline Establishment size $250+$ & $\begin{array}{l}-0.051 \\
(0.035)\end{array}$ & $\begin{array}{l}-0.061 \\
(0.050)\end{array}$ & $\begin{array}{l}-0.050 \\
(0.056)\end{array}$ \\
\hline Public sector & $\begin{array}{l}-0.019 \\
(0.022)\end{array}$ & $\begin{array}{l}0.021 \\
(0.034)\end{array}$ & $\begin{array}{l}-0.049 * * \\
(0.022)\end{array}$ \\
\hline Observations & 24,066 & 11,797 & 12,269 \\
\hline$R^{2}$ & 0.096 & 0.099 & 0.097 \\
\hline
\end{tabular}

Notes: The dependent variable is the standardised polychoric PCA index of overall job quality. The regressions also include occupation, industry, and country dummies. Standard errors clustered at the country level appear in parentheses. *** $p<0.01 ; * * p<0.05 ; * p<0.10$. 
Table A6: Using Log Income and Weekly Working Hours as Additional Controls

\begin{tabular}{llll}
\hline & (i) & (ii) & (iii) \\
& All & Men & Women \\
\hline Workers with the same title are mostly women & $-0.078^{* * *}$ & $-0.062^{* *}$ & $-0.081^{* * *}$ \\
& $(0.020)$ & $(0.028)$ & $(0.021)$ \\
Workers with the same title are mostly men & -0.037 & $-0.055^{* *}$ & -0.008 \\
& $(0.023)$ & $(0.024)$ & $(0.034)$ \\
Immediate boss is a woman & -0.019 & -0.032 & -0.015 \\
& $(0.015)$ & $(0.026)$ & $(0.021)$ \\
Observations & 24,066 & 11,797 & 12,269 \\
$R^{2}$ & 0.110 & 0.123 & 0.116 \\
\hline
\end{tabular}

Notes: The dependent variable is the standardised polychoric PCA index of overall job quality. Each regression includes log of monthly income and weekly working hours, and the control variables used in Table 3. Standard errors clustered at the country level appear in parentheses. ${ }^{* * *} p<0.01 ; * * p<0.05$; * $p<0.10$.

Table A7: Summary Statistics of the Potential Mediators

\begin{tabular}{llll}
\hline & (i) & (ii) & (iii) \\
& All & Male & Female \\
\hline Colleague help and support: & & & \\
Always & 0.41 & 0.39 & 0.42 \\
Most of the time & 0.38 & 0.39 & 0.37 \\
Sometimes & 0.15 & 0.16 & 0.14 \\
Rarely & 0.04 & 0.04 & 0.04 \\
Never & 0.03 & 0.02 & 0.03 \\
Discrimination on the basis of sex & 0.02 & 0.01 & 0.03 \\
Unwanted sexual attention & 0.02 & 0.01 & 0.03 \\
\hline
\end{tabular}

